\title{
Blended Learning Approach to Spoken English Teaching in M-learning
}

\author{
Shixiang LIU \\ Department of foreign languages and tourism, \\ Hainan College of Software Technology, \\ Qionghai 571400, China \\ xiangzi0223@126.com
}

\author{
Bingyan ZHU* \\ Department of foreign languages and tourism, \\ Hainan College of Software Technology, \\ Qionghai 571400, China \\ zhubingyan9@163.com* \\ ${ }^{*}$ Corresponding author
}

\begin{abstract}
With the rapid development of information network technology, the blended learning mode and quality resources in MOOCs(Massive Open Online Courses), Micro lectures, and APPs are changing the traditional classroom-based teaching. English learners can study at any time and any place with the mobile terminals, which provide better technical support and mechanism for personalized and cooperative English learning. Therefore, it is of significance to construct and practice blended spoken English learning and teaching mode based on $\mathrm{M}$ learning, which is conducive to further promoting the integration of information technology and EFL teaching, enriching the contents of spoken English teaching, improving the methods of spoken English teaching, practicing individualized English teaching, stimulating English learners' interests and motivations, and yielding more output of spoken English.
\end{abstract}

Keywords-blended learning; M-learning; spoken English; traditional teaching

\section{INTRODUCTION}

M-learning is changing the classroom-based traditional teaching mode. Therefore, it is clearly stated that information technology must be valued for it has a revolutionary impact on the development of education in the National Medium and Long-term Education Reform and Development Plan (20102020). In order to better implement the National Medium and Long-term Education Reform and Development Plan (20102020), the Ten Year Education Informatization Development Plan (2011-2020) was formulated by the Ministry of Education, holding that it is necessary to establish learners-centered teaching and learning mode by integrating up-to-date information technology and traditional teaching mode to make students easier adapt to the information era and internationalization. The contemporary college students, who are making the best of information technology based on their mobile terminals, are known as the Net Generation [1]. And they make mobile terminals access to the needed information anytime and anywhere.

M-learning, which evolves from D-learning and E-learning, is the new development of distance education, providing a good platform for lifelong learning. The report Mobile Learning Era was released by Empowering Technologies in 1998, and related studies were carried on since then in North America and Europe. The research team Mobile Education
Group was set up in the Berkeley Multimedia Research Center of University of California at Berkeley, conducting research on the application of mobile phones by middle school students in virtual university. Taking language teaching in Stanford University as a breakthrough, Stanford Learning Lab developed mobile learning model by integrating the foreign language learning and mobile instrument. Meanwhile, the European Commission also was leading a funded research project-MOBIlearn and M-learning. The former focused on developing situation teaching method based on mobile communication technology, while the latter aimed to develop some cheap, simple, practical products and services to meet needs of the EU citizens for information interaction and new learning experience. The Pan-European Research and Development Program funded by Information Society Technologies in European Commission is committed to providing education and learning for the poor people aged from 16 to 24 in the society. The forum Impact of Open Courseware on Higher Education in Developing Countries was held in Paris in July, 2002 by UNESCO, and the idea Open Educational Resources was proposed for the first time. With the great leap-forward development of mobile Internet technology, most free online MOOCs, such as Coursera, edX, Udacity, Khanacadem, and MOOC College by guokr.com, have been turning up one after another, which makes information technology-supported future university possible.

\section{LITERATURE REVIEW}

The studies on M-learning in China began in 2002, which is still in the primary stage, mainly characterized by the following features: transformation of English teaching method in the context of M-learning, survey of English learning under the background of M-learning, the application of APPs in English teaching practice, resource database construction in M-learning, flipped classroom based on mobile terminals, empirical study of the English comprehensive competence cultivation with the help of M-learning, and M-learning system design, development and application based on the mobile terminals. However, the number of studies integrating M-learning and oral English teaching and learning amounts to only 3, one of which is made by Zhou Chenrui, Sun Zhong, and Shen Haijiao who carried on a research based on the audiovisual APP Papa for one semester, finding that the accuracy, the number of 
sentences, and intonation of 72 subjects in primary school have been dramatically improved [2].

Blended learning, which is a formal education program combining face-to-face classroom method with computermediated activities, can make a student control over time, place, path, or pace while learning with the help of digital and online media. But there is no consensus on a definition of blended learning. Driscoll held that blended learning is a learning method that includes face-to-face, real time E-Learning and self-paced learning, which will become a learning trend with the combination of traditional and digital learning [3]. He Kekang argues that blended learning is to combine both the advantages of E-learning, M-learning and the traditional ways of teaching, which not only gives full roles of the teachers, as a guide and a monitor, but also fully reflects the students as the main role of learning to cultivate their initiative, enthusiasm and creativity of learning [4]. As blended learning was put forward in the context of M-learning, scholars have done many related studies. Ma Wulin and Zhang Xiaopeng conducted a study on the College English blended learning mode, indicating that blended English learning and teaching mode can solve the contradiction between limited capacity of classroom teaching and various needs of students' individualized learning, which effectively improved the quality of college English teaching [5] As the name suggests, blended learning is the combination of traditional classroom teaching and the modern information technology, and English teachers in M-learning or Blended learning should change or reshape their roles to adapt themselves to blended learning.

\section{BLENDED LEARNING-BASED SPOKEN ENGLISH LEARNING}

Spoken English is the most difficult part in EFL teaching and learning for most people, and how to teach or learn spoken English is one of the topics discussed most frequently home and abroad. With fewer and fewer hours allocated to spoken English both in primary school and in colleges or universities, it is necessary to probe into some new ways to teach or learn spoken English based on the blended learning in the context of M-learning.

\section{A. Needs Analysis and Blended Learning}

Needs analysis, widely applied in foreign language teaching, refers to the techniques and methods through introspection, interviews, observation and questionnaire. Hutchinson and Waters believe that learners' needs can be divided into learning needs and target needs. The former mainly refers to the learners' learning motivation, expectations and learning conditions, etc. And the latter refers to the acquired knowledge and skills for the future career [6]. Yang Jinrui and Ding Jing hold that the target needs is for social needs, i.e. students' competence expected by the society and the employers [7]. Dudley-Evans and St. John believed that it is necessary to take into account the following factors into consideration while doing students' needs analysis, such as the learners' current language level, the gap between the current and expected level, the tasks and activities that the learners want to accomplish with the language they have learned or acquired, what the learners want to obtain from the subject they study, how to make foreign language learners master and use appropriate expressions and techniques, what factors influence learners in studying, the effective ways to make up for the gap, and the factors related to learning context and atmosphere [8].

Constructing blended learning by integrating traditional classroom and online spoken English teaching, allows English learners to freely choose more suitable ways to study spoken English, more conveniently suitable spoken English tasks according to their own needs, more appropriate time to practice spoken English with people with different levels of English home and abroad in virtual network environment in M-learning The practice with the help of blended learning easier makes students understand spoken English learning objectives, better stimulate their motivations in learning spoken English, and more properly apply the spoken to the real communication environment.

\section{B. APPs and Blended Learning}

Due to the fact that the time allocated for College English has been on the decrease, it is of significance to adopt blended learning in the context of M-learning by integrating offline traditional English teaching in classroom and online practice. Therefore, English teachers should not only change the roles of traditional teacher but also reshape their new roles in $\mathrm{M}$ learning, such as English learning quality resource explorer, facilitator, coordinator, and cooperator [9]. On the other hand, English teachers should make full use of English self-learning softwares, APPs in particular, such as Basic spoken English, Fluent in English, Everspeak, 100TOEFL, SpeakingMax, Yeeaoobox, English at Hand by Oyell Internet Technology Co., New Concept English, and so on. As for the new spoken English beginners, they can choo se APPs,such as Basic spoken English, Fluent in English, according to their own interest. Because of the limited space, this article will focus on the Fun Dubbing which is compatible with Android and iOS.

The APP Fun Dubbing, which is one of the most useful and interesting software, is the first offline APP for English dubbing. The APP gathers the latest or most classic movies all over the world, TV series from the USA, animation, TED speech, songs, MVs, and a collection of other materials. And exclusive professional exams are launched with a most complete English learning system, making the mobile terminal users sharing their masterpieces, communicating with others online, and imperceptibly improve their spoken English while dubbing. Looking at the interface, the button dubbing is set at the lower left, with columns named a master show, popular videos, special collections, animation dubbing, celebrity speech, English learning by learning to music, and the latest dubbing. English masters' dubbing works are displayed in the Column a master show. And you can subscribe to some masters' works, by which you can communicate or discuss with others on the same topic in English. With regard to other columns, click on the corresponding more at right hand, you can access to what you are interested in, leveled simple, ordinary, and difficult in accordance to one's English.

Click on any video in the interface, and we can see the video is limited to $1 \sim 2$ minutes. After watching several times, students can push the button $I$ want to dub below the video; the video will be dubbed by sentence-to-sentence segmentation. 
The learners should save the dubbing, and they can share their masterpiece in WeChat, $Q Q$, or $Q Q$ group, etc. for communication, study or comment with or by others. Meanwhile, learners can click on the button Group with columns for workers, possible exam takers, spoken English practice, something else, and so on. Learners can also find the group or create a group according to their own needs by clicking on the button my team which helps you query learning history. If the students click on the button Top ones, you can find a great many works form the whole country, the specific provinces where they live, and dubbing enthusiasts from the same school. Last but not the least, Teachers can create a group and invite their students to join, which can help teachers to set some homework and monitor their progress at any time or any place. Besides, both teachers and students can be the coach as long as they are good at spoken English, with fans amounting to 100 and at least 30 shared works.

\section{Achievements' Full Display and Summative Assessment}

Personalized learning and cooperative learning is more applicable in M-learning due to the fact that the students can choose the tasks as they wish according to their English level. Therefore, blended learning mode can better meet the students' needs to learn spoken English whether they are good at English or not. At the beginning of each term, the students should be divided into several groups according to their free choice, with the most suitable one in a certain group selected the leader. The one chosen as the leader is responsible for encouraging group members to collect high quality resources, theme activity organizing and planning, scoring group members according to the division and completion of tasks, and finished tasks uploading, and so on [10]. Taking Unit 3 Speaking in An Integrated Skills Course ( $2^{\text {nd }}$ Edition) as an example, the English teacher should ask students to look for as many materials, such as links, videos, books, and magazines, as possible related to the topic Do you like Western food? Why or why not?. And upload all the materials available to the $Q Q$ group or WeChat to share with all the group members a week before the topic has been discussed. The group members should watch or read again and again, summarize some related information, record some videos, and editing or rearranging the answers many a time till the deadline or the overwhelming majority of the group members are satisfied with the masterpiece they have accomplished. During the process, all the group members are asked to be involved into airing out their own ideas, watching the videos, and putting up with some advice, which will be scored by the group leader according to what they have done. If they are confronted with any problem, discussion within group or between group, even with English teacher and others is encouraged, this may be scored more by English teacher.

Dai Jiagan held that it is imperative that the traditional examination system with single written tests focused on be replaced with multiple evaluation system to improve the quality of education, which should be the core of the education reform [11]. The textbook College English Curriculum Requirements (Revised) was released by the Ministry of Education in 2007, holding that the teaching evaluation of students' learning should adopt formative assessment and summative assessment. And formative assessment refers to procedural and developmental assessment conducted through the whole teaching process, i.e., tracking the entire teaching process, providing real-time feedback and boosting an allround development of the students by means of various evaluative methods. Formative assessment can be descriptive evaluation, rating or score evaluation record, with common forms listed as follows [12]:

- Classroom observation record by teachers, a dynamic record of students' classroom performance and evaluation of students' questions and answers;

- Establishing a portfolio, questionnaire or interview about learning carried out timely to know more about learners' attitude, emotion, learning strategies and make evaluation in time;

- Conducting peer assessment and self-assessment on the dynamic teaching and learning process, by students themselves, fellow classmates, teachers, parents, and others;

- Keeping records of one's understanding and introspection based on group discussion or dialogue within group members and between teachers and students, which should be checked regularly and evaluated properly by teachers;

- Checking homework and doing some quiz.

Formative assessment facilitates the effective monitoring of students' autonomous and cooperative learning, and is particularly important in implementing blended learning based on traditional teaching and M-learning, keeping a record of students' activities inside and outside classroom and online self-learning data, keeping files on students' study outcomes, which allows students' learning processes to be subject to observation, evaluation and supervision, thus contributing to improving spoken English learning efficiency. Therefore, quantitative statistics should be adopted to record how many times the video has been watched, commented, discussed, homework completion, classroom attendance, classroom presentation, group planning, self-assessment, peer assessment, inter-group assessment. It is of great value to make best of the mobile wireless network to share resources and display the results of the peer assessment, self-assessment, and inter-group assessment real-time by combining formative and summative assessment to support blended learning.

\section{CONCLUSION}

The mobile terminal-based spoken English teaching in blended learning mode, which is breaking the limits of time and space, has been exerting far-reaching influence on traditional English teaching in China. The practice indicates the spoken English teaching in blended learning mode can better meet the needs of personalized learning for the post-1990s, and boost further the cooperative learning in the virtual environment. Therefore, English teachers should change their educational concepts to some extent, establish and practice spoken English teaching in blended learning mode, combining traditional spoken English teaching in classroom and online 
self-learning with some excellent information or technologybased platforms and APPs to guide the students to make the best of their mobile terminals to improve their spoken English.

\section{ACKNOWLEDGMENT}

This work was financially supported by Hainan Education Sciences Planning Office (No. QJY1251557) and Hainan College of Software Technology (No. Hr201604)

\section{REFERENCES}

[1] Oblinger, D. G. and Oblinger, J. L, Educating the Net Generation. Washington, DC: Educause, 2005.

[2] Chenrui Zhou , Zhong Sun, and Haijiao Shen, "Empirical Study on Students' Spoken English in Primary School Based on APP Papa,” eEducation Research, vol.268, pp.87-94, August. 2015.

[3] Driscoll, M, “Blended learning: Let’s get beyond the hype,” E-learning, vol.1, pp.61-68, Jan. 2002.

[4] Kekang He, "On the New Development of Education Technology from the the perspective of Blending Learning," e-Education Research, vol.132, pp.1-6, March. 2004.
[5] Wulin Ma andXiaopeng Zhang, Research and Practice on College English Blended Model, Computer-assisted Foreign Language Education, vol.139, pp.50-57, May. 2011.

[6] Hutchinson,T. and A. Waters, English for Specific Purpose. Cambridge: Cambridge University Press, 1987.

[7] Jinrui Yang and Jing Ding, "A Needs-Analysis-Based Survey of the Curriculum Design for Undergraduate Translation Majors Exemplified by a University in Shandong Province," Shandong Foreign Language Teaching, vol.156, pp.74-82, Oct. 2013.

[8] Dudley-Evans, T. and St. John, Development in English for Specific Purposes. Cambridge: Cambridge University Press, 1998.

[9] Shixiang Liu and Bingyan Zhu, “On EFL Teachers' New Roles in Elearning," in Advances in Social Science Education and Humanities Research, vol. 28, Xiaonan Xiao, Eds. Paris: Atlantis Press, 2015, pp. 93-96.

[10] Bingyan Zhu, Shixiang Liu, Li Wu, and Hanying Guo, "Applying Multiple Assessments to English Experimental Teaching in Higher Vocational Vocational College,"Journal of Wuhan Polytechnic, vol.12, pp. 50-54, DEC. 2013.

[11] Jiagan Dai, To Improve Our Tests. Beijing: Higher Education Press, 2008.

[12] Shan Kong, "To Improve Vocational English Teaching with Summatvie Assessment,” China Adult Education, vol.10, pp. 170-171, OCT. 2006. 